\title{
TRIGO: ÉPOCAS DE SEMEADURA EM ASSIS (VALE DO PARANAPANEMA), SP, NO PERÍODO 1978-82(')
}

\author{
JoÃo CARLoS FELÍCIO (2,4), CARLOS EDUARDO dE OLIVEIRA CAMARGO (2,9), \\ ANTONIO WILSON PENTEADO FERREIRA FILHO (2,4), \\ JOSÉ GUILHERME DE FREITAS (2.4) \& MARIO JOSÉ PEDRO JÚNIOR (3.4)
}

\begin{abstract}
RESUMO
Avaliaram-se os resultados de rendimento dos cultivares de trigo CNT-8, IAC-17 a BH-1146 em oito épocas de semeadura (a primeira no primeiro decêndio de março e a última no terceiro decêndio de maio), na Fazenda Canadá, em Assis (SP), durante o qüinqüênio 1978/82. Em cada época de semeadura, efetuaram-se avaliaçōes de rendimento de grāos $\theta$ altura de plantas. A disponibilidade hídrica do solo para a cultura foi caracterizada através de balanço hídrico decendial, considerando $125 \mathrm{~mm}$ como a capacidade máxima de retençāo de água no solo. Os resultados indicaram como a melhor faixa de semeadura, independente de cultivar, o período compreendido entre o terceiro decêndio de março e o primeiro decêndio de abril. Indicaram, também, que os períodos extremos estudados säo pouco favoráveis à semeadura do trigo na regiāo. O cultivar CNT-8 foi o mais produtivo, de maior porte de planta, independente do ano e da época de semeadura. Entre os anos em estudo, destacou-se o de 1979, cujos cultivares de trigo exibiram as maiores produçōes de grāos, em vista das condiçōes climáticas favoráveis para a cultura.
\end{abstract}

Termos de indexação: trigo, cultivares CNT-8, IAC-17 e BH-1146, produção de grăos, altura das plantas, época de semeadura, balanço hídrico.

\begin{abstract}
WHEAT: SEEDING TIMES AT ASSIS, PARANAPANEMA VALLEY, STATE OF SÄO PAULO, BRAZIL, DURING THE PERIOD 1978-1982

This paper presents the behaviour of three wheat cultivars (CNT 8, IAC 17 and $\mathrm{BH}-1146$ ) at eight seeding times (the first seeding time was from 1 st to 10 th of
\end{abstract}

(') Parcialmente financiado pelo Convênio IAC/Cooperativas dos Produtores Rurais do Vale do Paranapanema/Secretaria de Agricultura e Abastecimento. Recebido para publicaçăo em 25 de setembro de 1990 e aceito em 30 de março de 1991. (SP).

(') Seçāo de Arroze Cereais de Inverno, Instituto Agronômico (IAC), Caixa Postal 28, 13001 Campinas

(3) Seçäo de Climatologia Agrícola, IAC.

(4) Com bolsa de pesquisa do CNPq. 
March and the last one from to 20th to 30th of May) in experiments carried out at Canadá Farm, Assis, State of São Paulo, Brazil, in the period 1978-1982. Grain yield and plant heigth were evaluated for each seeding time, in each experiment. Soli water avallability was obtained by water balances taken at each ten days considering $125 \mathrm{~mm}$ as the soil water retention capacity. The results showed that the seeding time from 20th of March to 10 th of April was the best considering grain yield, independently of the cultivar. The results also indicated that the others studied seeding times were not favourable to seed wheat in this region. The wheat cultivar CNT 8 was the most productive, independently of the year and the seeding time. Considering the years under study it was observed that in 1979, the three evaluated cultivars exhibited the highest grain yield due meanly to the climatic conditions which was favourable to the crop.

Index terms: wheat, CNT-8, IAC-17 and $\mathrm{BH}-1146$ cultivars, grain yield, plant height, seeding times, water balance.

\section{INTRODUÇĀO}

O trigo é a cultura de maior expansāo mundial em área cultivada (MOTA, 1982). Originário do Sudeste da Ásia, foi introduzido na Índia, na China e na Europa desde 5000 anos a.C. Atualmente, cultivam-se variedades adaptadas desde o - Equador até $60^{\circ}$ de latitude $\mathrm{N}$ ou S. As migraçōes do trigo em direçāo aos pólos e ao Equador têm sido propiciadas tanto pela seleçāo natural como pela criaçáo de novos cultivares adaptados a condiçóes ambientais específicas.

Segundo TEIXEIRA (1958), a segurança das colheitas está diretamente ligada à observância da melhor época de semeadura. É de estranhar quẹ, até meados da década de 70 , ainda não houvesse uma concordância entre os técnicos que atuavam com a cultura do trigo, na definição da melhor época de semeadurá para as diferentes regióes paulistas.

BAYMA (1960) comenta que fatores meteorológicos como chuva, calor, frio, luz solar, umidade do ar e do solo e vento afetam o desenvolvimento do trigo, com maior ou menor intensidade, conforme as diferentes fases de seu ciclo vegetativo.

A diversificação de regiōes produtoras é muito importante, visto que, na regiāo tradicional de clima temperado, ocorrem anos de fracassos, embora tenha sido constante o crescimento da área de cultivo e a produção por área (MOTA, 1982). É interessante notar, ainda, a injustificável redução da área de semeadura após anos de fracasso, pois, em geral, seguem-se-lhes anos de bons rendimentos. Segundo SILVA (1971), a regiāo de transiçāo entre o clima temperado e o tropical, no Norte e Oeste do Paraná, no Sul do Mato Grosso do Sul e no Oeste de São Paulo, representa uma nova fronteira agrícola para a triticultura nacional,

No Centro-Suido Estado, otrigo encontra normalmente umidade suficiente no solo, após a colheita da soja, para o desenvolvimento da cultura, e apresenta colheitas satisfatórias, quando semeado em abril (CAMARGO, 1971). 
Os objetivos do presente trabalho foram: (a) determinar o efeito de épocas diferenciadas de semeadura sobre o rendimento de gräos em cultivares de diferentes grupos bioclimáticos, e (b) avaliar as causas ecoclimáticas e quantificar seus efeitos, determinando os períodos críticos e os fatores limitantes da produção de trigo.

\section{MATERIAL E MÉTODOS}

Três cultivares de trigo, pertencentes a grupos bioclimáticos diferentes IAC-17 (de ciclo superprecoce, com maturaçāo de 115 dias), $\mathrm{BH}-1146$ (de ciclo precoce, com maturaçāo de 116 a 125 dias) e CNT-8 (de ciclotardio, com maturaçăo acima de 130 dias) - foram semeados em oito épocas, divididas em decêndios: para a primeira época, considerou-se o período compreendido pelo primeiro decêndio de março e para a oitava e última época, o segundo de maio, abrangendo o quinquênio 1978-82, na Fazenda Canadá, município de Assis, oeste do Estado de São Paulo, localizada na latitude de $22^{\circ} 40^{\prime} \mathrm{S}$; longitude $50^{\circ} 25^{\prime} \mathrm{W}$ e altitude de $569 \mathrm{~m}$. O clima é classificado como Cfa, mesotérmico úmido, sem estiagem, em que a temperatura média do mês mais quente é maior do que $22^{\circ} \mathrm{C}$, apresentando o mês mais seco, acima de 30mm de precipitaçäo pluvial (KALCKMANN et al., 1965).

Retiraram-se amostras do solo do local e, de acordo com os resultados analíticos, efetuou-se a adubaçāo, empregando-se os seguintes adubos: sulfato de amônio com $20 \%$ de $\mathrm{N}$; superfosfato simples com $20 \%$ de $\mathrm{P}_{2} \mathrm{O}_{5}$ e cloreto de potássio com $60 \%$ de $\mathrm{K}_{2} \mathrm{O}$, aplicados a lanço antes da semeadura e, posteriormente, incorporados ao solo. A quantidade de fertilizante empregada nas diferentes épocas e anos baseou-se nas tabelas de adubaçāo e calagem do Instituto Agronômico (RAlJ et al., 1985)

O delineamento estatístico empregado foi o de blocos ao acaso com parcelas subdivididas distribuídas ao acaso dentro de cada parcela, com quatro repetiçōes por local.

As parcelas de cada ensaio foram constituídas de cinco linhas de $5 \mathrm{~m}$ de comprimento, espaçadas de $0,20 \mathrm{~m}$, deixando-se um espaçamento lateral entre cada parcela de $0,60 \mathrm{~m}$ e de $1 \mathrm{~m}$ entre repetiçōes. Efetuou-se o plantio na base de 80 sementes viáveis por metro linear de sulco, equivalendo a 400 sementes por metro quadrado. Na semeadura de cada época, tomou-se a precauçăo de irrigar as subparcelas (cultivares) recém-semeadas para garantir a emergência.

$\mathrm{Na}$ colheita, tomaram-se cinco linhas de cada subparcela, correspondendo a uma área útil de $5 \mathrm{~m}^{2}$.

Os dados termopluviométricos diários relativos aos períodos considerados foram obtidos no Posto Meteorológico da Fazenda Canadá, representativo de toda a regiāo estudada. 
A caracterização da disponibilidade hídrica foi efetuada através do balanço hídrico decendial (dez dias), segundo o método de THORNTHWAITE \& MATHER (1955), considerando $125 \mathrm{~mm}$ como capacidade máxima de retenção de água no solo. Os balanços hídricos foram calculados para os meses de março a outubro, referentes ao período 1978-82 (Figuras 1-5).

A altura das plantas de cada cultivar foi medida no campo, levando-se em consideraçāo a distância do nível do solo ao ápice da espiga, desprezando-se as aristas e mantendo-se a planta esticada em todos os anos, com exceção de 1978.

Os dados de produçăo e de altura das plantas foram submetidos à análise estatística segundo o modelo para grupos de experimentos, de acordo com PIMENTEL GOMES (1970).

\section{RESULTADOS E DISCUSSÃO}

CAMARGO et al. (1986) definem como padróes climáticos normais para o Estado de Săo Paulo os períodos: outubro-março, quando a precipitação pluvial excede a evapotranspiraçăo, e abril-setembro, quando, após equilíbrio entre essas variáveis no início da estação, a evapotranspiraçāo torna-se maior que a precipitaçāo, resultando em período normal de seca (deficiência hídrica). Balanços hídricos decendiais do Vale do Paranapanema, referentes a 1978-82 (Figuras 1-5), demonstram períodos com deficiência hídrica durante o inverno; excetuando o ano de 1982, com excedente hídrico anormal (junho-julho). O excesso de umidade nesse período é prejudicial à planta de trigo, segundo LUZ (1982) e FELICIO et al. (1986, 1988), favorecendo a ocorrência de manchas foliares, causadas por Helminthosporium sp., Septoria nodorum Berk e Septoria tritici Rob. ex Desm.

A análise da variância conjunta - Quadro 1 - dos dados obtidos de rendimento de grăos e altura das plantas mostrou efeitos significativos para anos; épocas de semeadura; cultivares; interaçōes cultivares $x$ anos, cultivares $x$ épocas de semeadura; épocas de semeadura $x$ anos, e cultivares $x$ anos $x$ épocas de semeadura.

Os dados obtidos nas oito épocas de semeadura no quinquênio 1978-82 encontram-se no quadro 2 . O efeito de época de semeadura no período, integrando um conjunto de elementos meteorológicos sobre o comportamento dos diferentes cultivares, determinou a variabilidade do rendimento de grăos ao longo das épocas de semeadura. Tais dados indicam que a melhor época de semeadura se situou no período compreendido entre o terceiro decêndio de março e o primeiro decêndio de abril; o decêndio que antecedeu o período citado como o que o sucedeu também seriam favoráveis à semeadura na regiāo. Os períodos decendiais extremos foram pouco favoráveis à instalação da cultura, ou seja, a primeira época (primeiro decêndio de março) e a oitava (segundo decêndio de maio). 


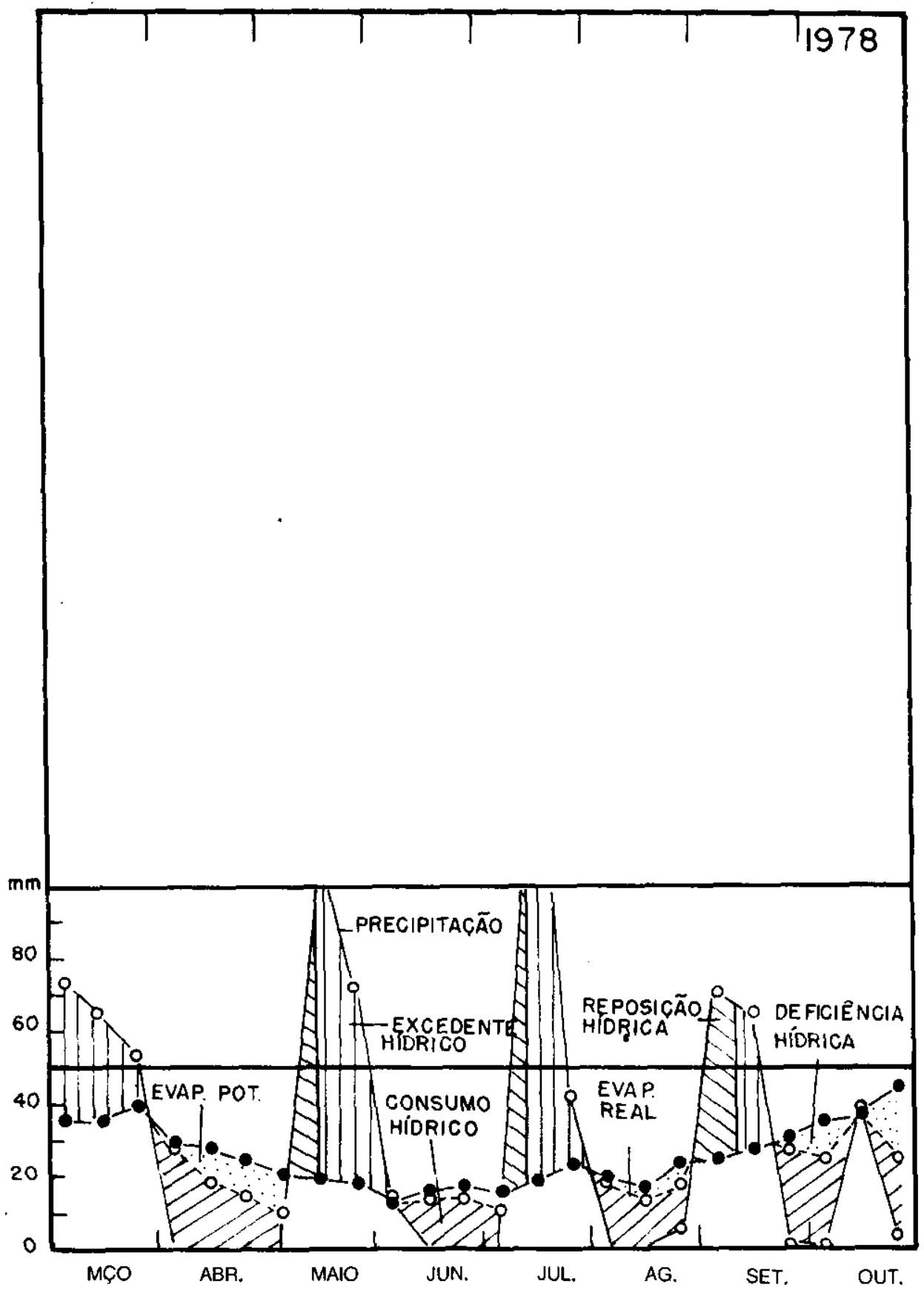

FIGURA 1. Balanço hídrico decendial, pelo método de THORNTHWAITE \& MATHER (1955) (125mm), em 1978. 


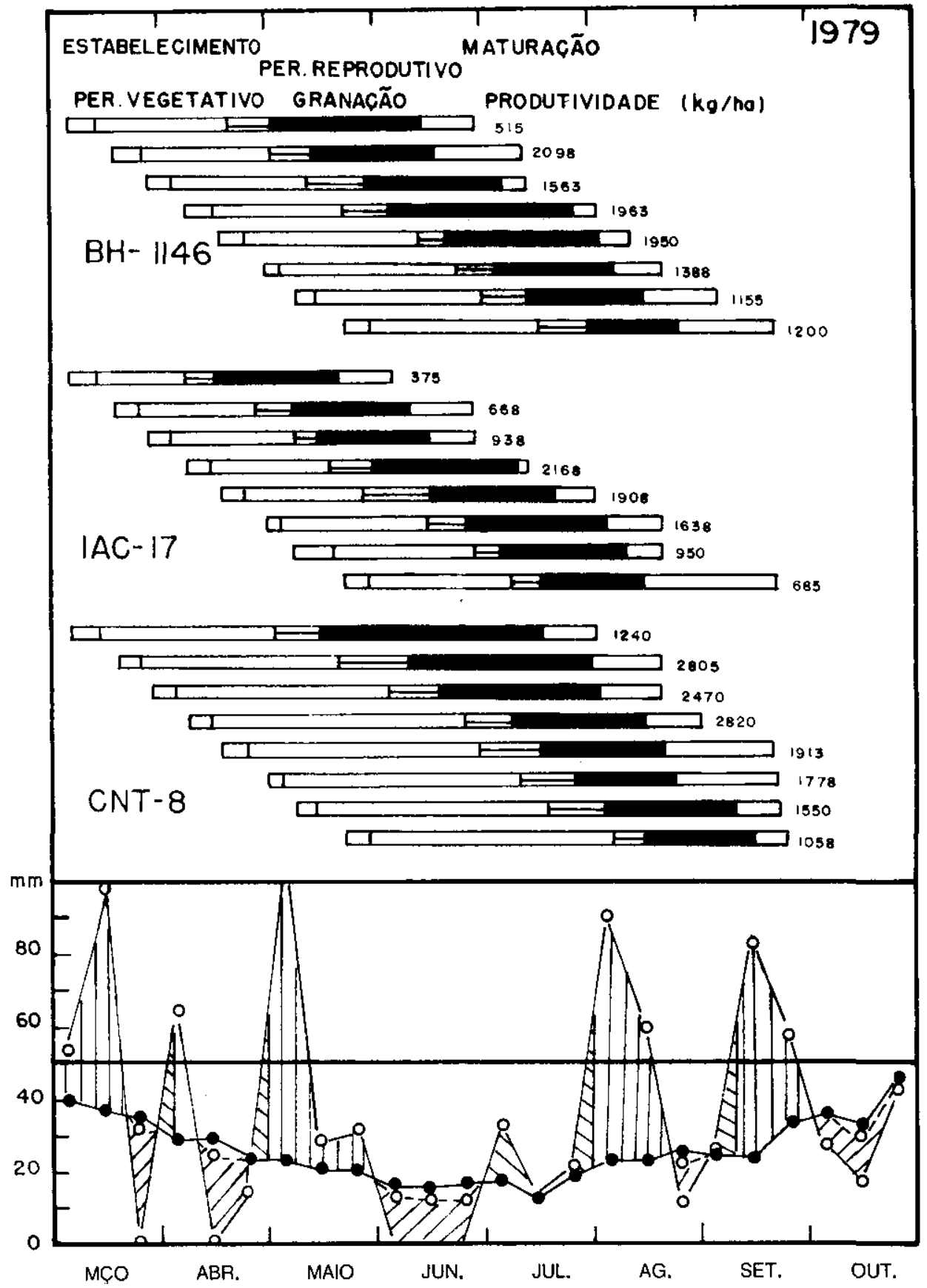

FIGURA2. Balanço hídrico decendial, pelo método de THORNTHWAITE \& MATHER (1955) $(125 \mathrm{~mm})$ e anotaçōes fenológicas dos três cultivares de trigo em 1979. 


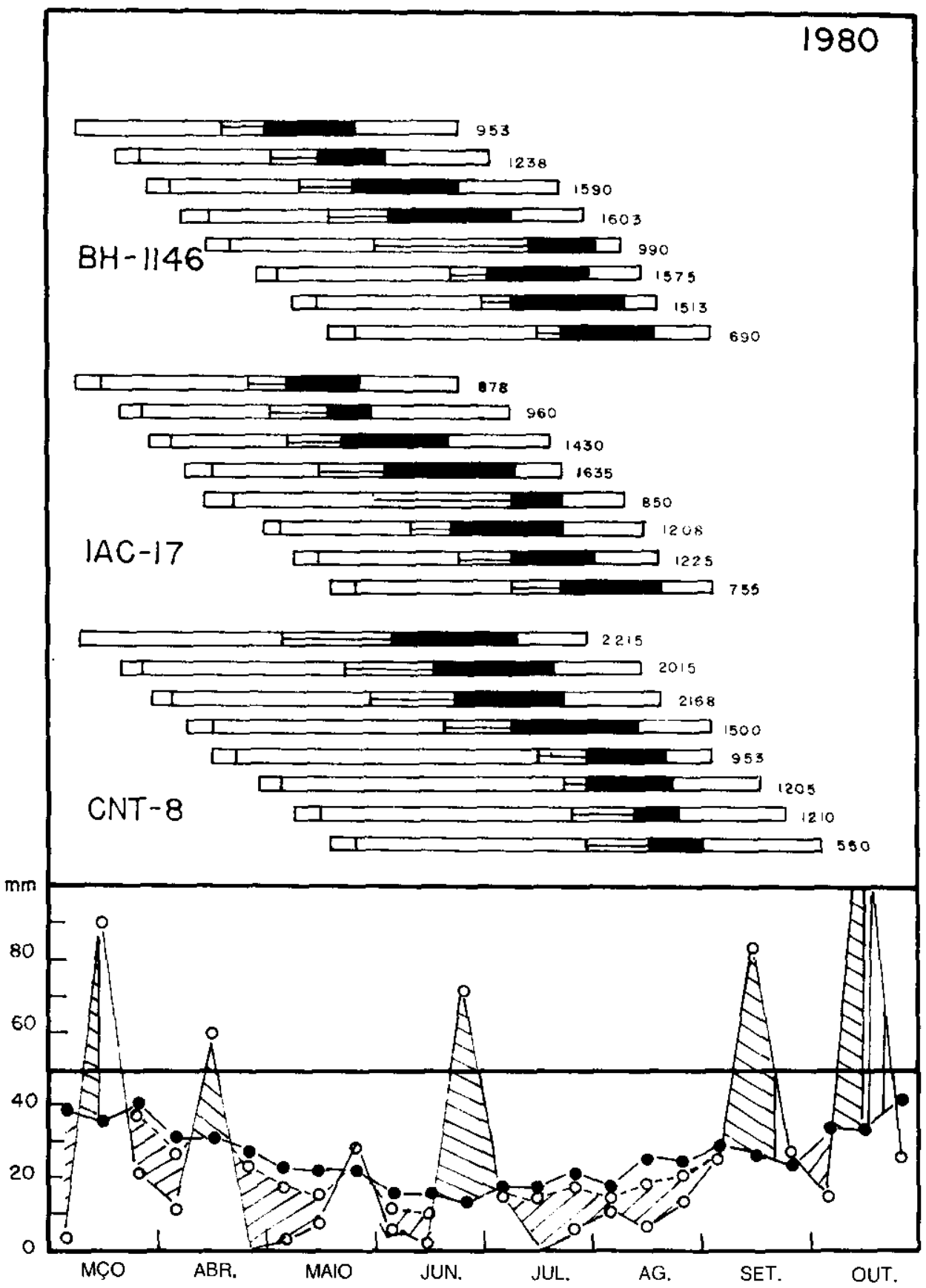

FIGURA 3. Balanço hidrico decendıat, pelo método de THORNTHWAITE\& MATHER (1955) $(125 \mathrm{~mm})$ e anotações fenológicas dos três cultivares de trigo em 1980. 


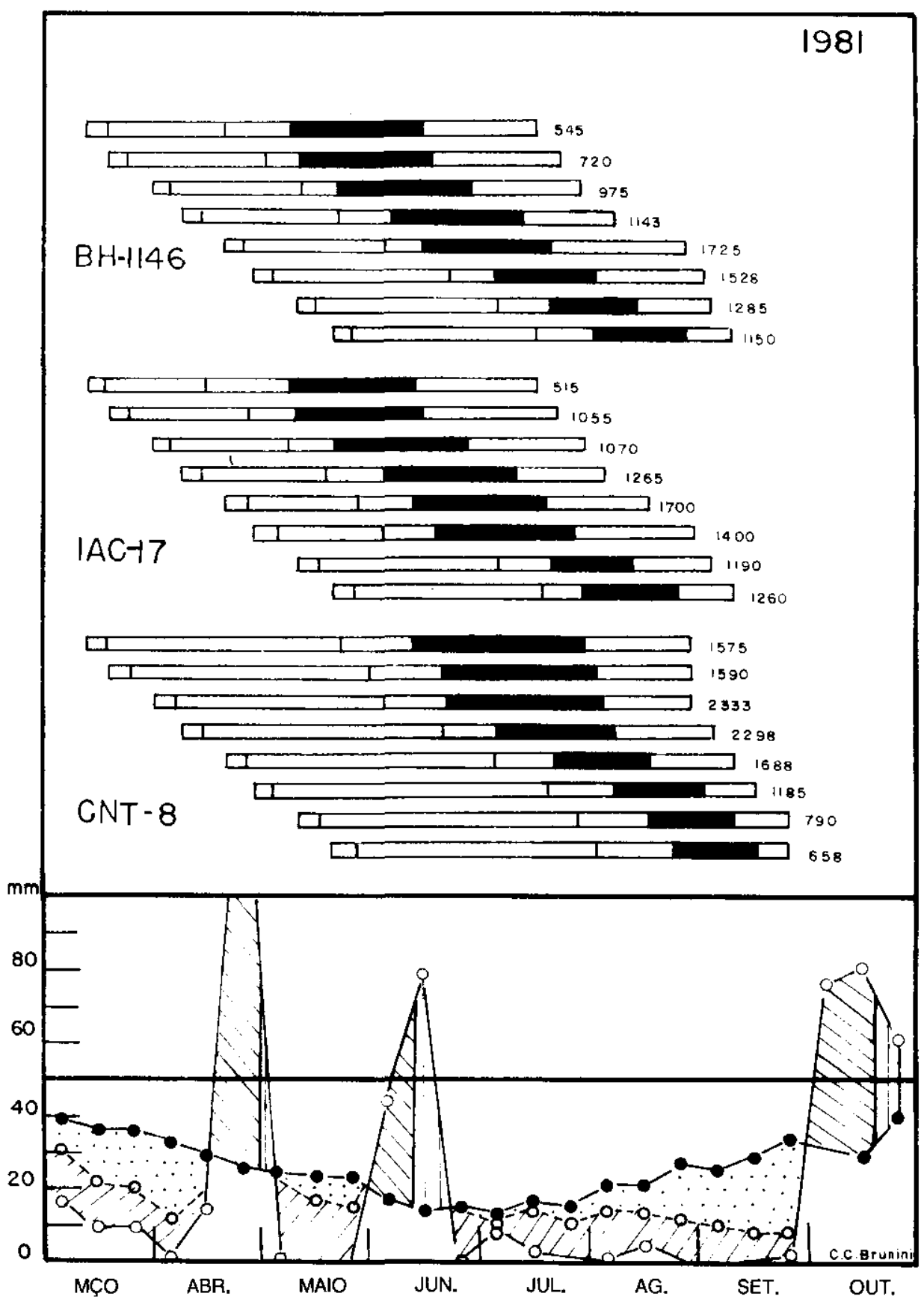

FIGURA 4. Balanço hídrico decendial, pelo método de THORNTHWATTE\& MATHER (1955) (125mm) e anotaçōes fenológicas dos três cultivares em 1981. 
TRIGO: ÉPOCAS DE SEMEADURA EM ASSIS...

123

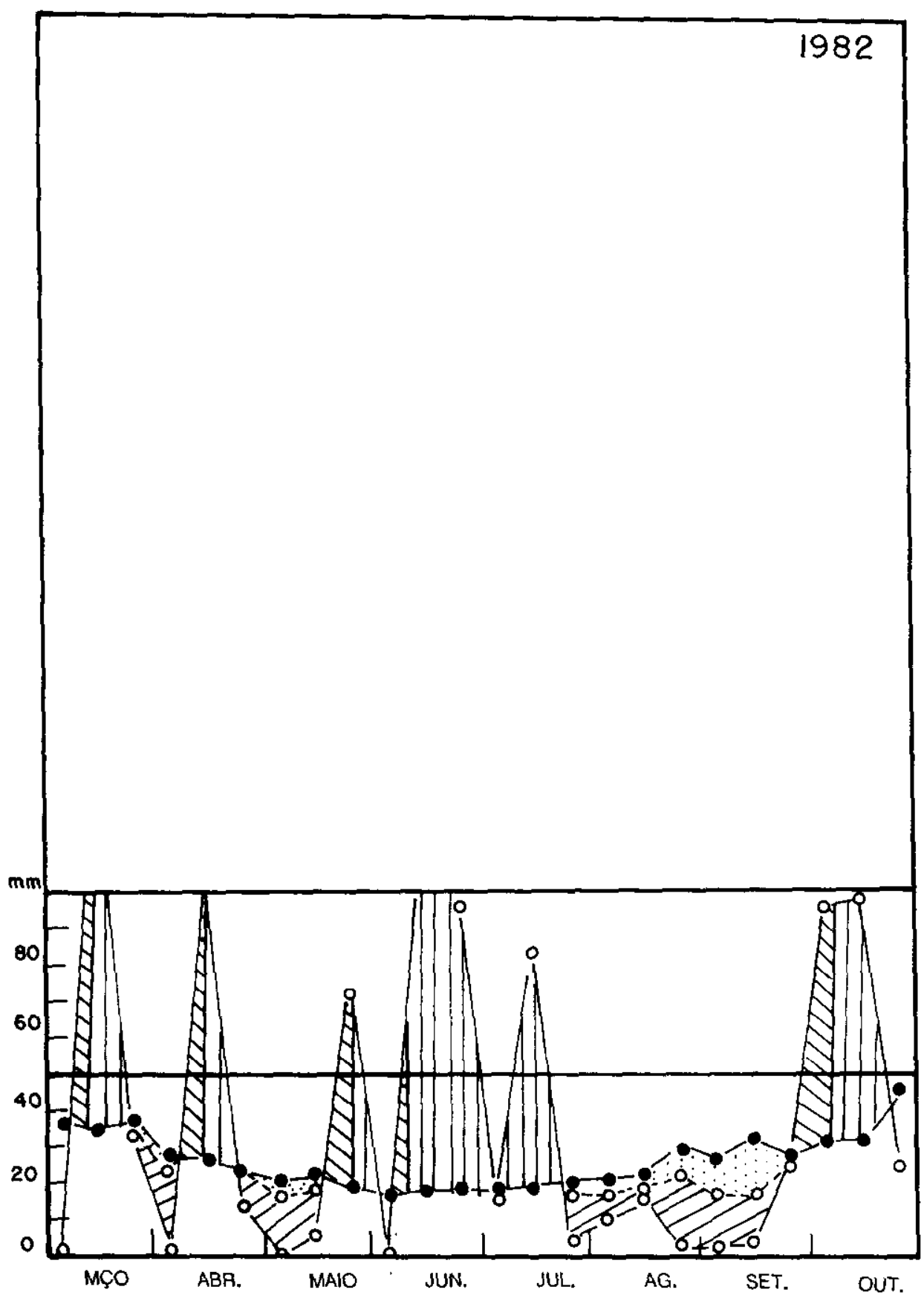

FIGURA 5. Balanço hidrico decendial, pelo método de THORNTHWAITE \& MATHEA (1955) $(125 \mathrm{~mm})$ em 1982.

Bragantia, Campinas, 50(1):115-128, 1991 
QUADRO 1. Quadrados médios da análise da variância para rendimento de grãos e altura das plantas dos cultivares de trigo estudados em oito épocas de semeadura, em Assis (SP), no período 1978-82

\begin{tabular}{|c|c|c|c|c|}
\hline \multirow{2}{*}{$\begin{array}{l}\text { Causas } \\
\text { đe Variaçāo }\end{array}$} & \multicolumn{2}{|c|}{$\begin{array}{c}\text { Rendimentos } \\
\text { de grãos }\end{array}$} & \multicolumn{2}{|c|}{$\begin{array}{c}\text { Altura } \\
\text { das plantas }\end{array}$} \\
\hline & $\mathrm{GL}$ & Q.M. & GL & Q.M. \\
\hline Anos $(A)$ & 4 & $19.580 .923,10^{\star}$ & 3 & $2.887,79^{*}$ \\
\hline 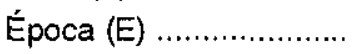 & 7 & $2.952 .808,55^{\star}$ & 7 & $2.202,29^{\star}$ \\
\hline 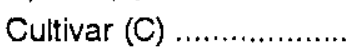 & 2 & $7.069 .593,48^{\star}$ & 2 & $15.476,52^{\star}$ \\
\hline Interaçāo C x A ............... & 8 & $613.399,81$ & 6 & $585,46^{\star}$ \\
\hline Interaçăo C x E .............. & 14 & $793.562,98^{\star}$ & 14 & $681,84^{\star}$ \\
\hline Interação Ex A ............. & 28 & $1.151 .264,67^{\star}$ & 21 & $613,12^{\star}$ \\
\hline Interação $C \times A \times E \ldots \ldots .$. & 56 & $372.114,77^{\star}$ & 42 & $98,67^{\star}$ \\
\hline 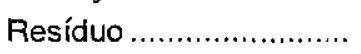 & 360 & $70.426,26$ & 288 & 26,06 \\
\hline
\end{tabular}

* Significativo ao nível de $5 \%$

Nos dados do quadro 2 e nos balanços hídricos decendiais para os períodos analisados (Figuras 1 a 5), verifica-se que os anos se apresentaram sob várias condiçóes meteorológicas, influenciando diretamente a produtividade do trigo. O ano de 1979 apresentou a melhor produção de grăos, vindo a seguir o biênio 1980/81, que nāo diferiram entre si; entretanto, baixas produtividades ocorreram em 1982, devido ao excesso de umidade, e em 1978, à deficiência hídrica acentuada no início da implantaçāo da cultura (março-abril). De acordo com PERRIN-JAQUET (1951), a falta de água diminui o número de espiguetas e de flores férteis por espigueta se ocorrer durante as três semanas que antecedem o espigamento (fase vegetativa), influindo na produtividade.

$\mathrm{Na}$ análise do comportamento produtivo dos cultivares em cada época em estudo - Quadro 3 - verificou-se que o cultivar de ciclo tardio CNT-8 foi superior aos outros dois. As melhores faixas de semeadura para os cultivares, segundo o seu grupo bioclimático, situam-se de 20/3 a 10/4, com rendimento máximo em 30/3 para o 'CNT-8', de ciclo tardio; para o 'BH-1146', de ciclo precoce, a melhor faixa foi de 20/3 a 30/4, com o máximo rendimento em 20/4, e para o 'IAC-17', do grupo bioclimático superprecoce, o rendimento máximo ou ótimo foi obtido em 10/4, sendo sua faixa de melhor rendimento entre 10 e $30 / 4$.

As variedades brasileiras de trigo, segundo OSÓRIO (1982), de modo geral, apresentam porte alto, especialmente as semeadas ao sul do paralelo $24^{\circ} \mathrm{S}$. 
QUADRO 2. Rendimento médio de grãos de trigo em oito épocas de semeadura estudadas no qüinqüênio 1978-82, no Vale do Paranapanema, município de Assis, SP

\begin{tabular}{llllllll}
\hline Época & Data & 1978 & 1979 & 1980 & 1981 & 1982 & Média \\
\hline & & & & & & & \\
$19 \ldots \ldots$ & $10 / 03 \ldots \ldots$ & $126 \mathrm{~d}$ & $723 \mathrm{e}$ & $1.365 \mathrm{bc}$ & $878 \mathrm{~d}$ & $942 \mathrm{ab}$ & $807 \mathrm{e}$ \\
$2^{\mathrm{a}} \ldots \ldots$. & $20 / 03 \ldots \ldots$ & $568 \mathrm{ac}$ & $1.858 \mathrm{bc}$ & $1.404 \mathrm{bc}$ & $1.121 \mathrm{bc}$ & $759 \mathrm{~b}$ & $1.142 \mathrm{bc}$ \\
$3^{\mathrm{a}} \ldots \ldots$ & $30 / 03 \ldots \ldots$ & $379 \mathrm{~cd}$ & $1.656 \mathrm{bc}$ & $1.730 \mathrm{a}$ & $1.459 \mathrm{ab}$ & $1.114 \mathrm{a}$ & $1.268 \mathrm{ab}$ \\
$4^{\mathrm{a}} \ldots \ldots$ & $10 / 04 \ldots \ldots$ & $351 \mathrm{~cd}$ & $2.316 \mathrm{a}$ & $1.595 \mathrm{ab}$ & $1.568 \mathrm{ab}$ & $686 \mathrm{ab}$ & $1.303 \mathrm{a}$ \\
$5^{\mathrm{a}} \ldots \ldots$. & $20 / 04 \ldots \ldots$ & $461 \mathrm{~b}$ & $1.941 \mathrm{~b}$ & $932 \mathrm{~d}$ & $1.704 \mathrm{a}$ & $669 \mathrm{bc}$ & $1.141 \mathrm{bc}$ \\
$6^{\mathrm{a}} \ldots \ldots$. & $30 / 04 \ldots \ldots$ & $763 \mathrm{ab}$ & $1.600 \mathrm{c}$ & $1.264 \mathrm{c}$ & $1.304 \mathrm{bc}$ & $390 \mathrm{~cd}$ & $1.064 \mathrm{~cd}$ \\
$7^{\mathrm{a}} \ldots \ldots$. & $10 / 05 \ldots \ldots$ & $805 \mathrm{a}$ & $1.206 \mathrm{~d}$ & $1.265 \mathrm{c}$ & $1.088 \mathrm{~cd}$ & $355 \mathrm{~d}$ & $944 \mathrm{~d}$ \\
$8^{\mathrm{a}} \ldots \ldots$. & $20 / 05 \ldots \ldots$ & $495 \mathrm{ac}$ & $974 \mathrm{de}$ & $681 \mathrm{~d}$ & $1015 \mathrm{~cd}$ & $172 \mathrm{~d}$ & $677 \mathrm{f}$ \\
Média & & $493 \mathrm{D}$ & $1.535 \mathrm{~A}$ & $1.280 \mathrm{~B}$ & 1.2678 & $636 \mathrm{C}$ & \\
\hline
\end{tabular}

Médias seguidas por letras distintas diferem entre si no sentido vertical para épocas e no sentido hurizontal para anos ao nível de significância de $5 \%$ pelo teste de Duncan.

QUADRO 3. Rendimento médio de grãos de trigo dos cultivares IAC-17, BH-1146 e CNT-8, em oito épocas de semeadura, no qüinqüênio 1978-82 no Vale do Paranapanema, município de Assis, SP

\begin{tabular}{|c|c|c|c|c|}
\hline Época & Data & IAC-17 & $\mathrm{BH}-1146$ & CNT 8 \\
\hline & & \multicolumn{3}{|c|}{$\mathrm{Kg} / \mathrm{ha}$} \\
\hline $1 \mathrm{~A} \ldots \ldots \ldots \ldots$ & $10 / 03 \ldots \ldots \ldots \ldots$ & $519 e$ & $625 d$ & $1.278 b$ \\
\hline $2^{\mathrm{a}} \ldots \ldots \ldots \ldots \ldots$ & $20 / 03 \ldots \ldots \ldots \ldots . . . .$. & 731de & $1.096 \mathrm{ab}$ & $1.599 \mathrm{a}$ \\
\hline $3^{\mathrm{a}} \ldots \ldots \ldots \ldots$ & $30 / 03 \ldots \ldots \ldots \ldots . . . . . .$. & $935 b d$ & $1.105 a b$ & $1.763 a$ \\
\hline $4^{\mathrm{a}} \ldots \ldots \ldots \ldots . . . . .$. & $10 / 04 \ldots \ldots \ldots \ldots$ & $1.196 \mathrm{a}$ & $1.127 \mathrm{a}$ & $1.587 a$ \\
\hline $5^{\mathbf{a}} \ldots \ldots \ldots \ldots . . . .$. & $20 / 04 \ldots \ldots \ldots \ldots . . . .$. & $1.144 a b$ & $1.153 a$ & $1.128 b$ \\
\hline$\sigma^{a} \ldots \ldots \ldots \ldots$ & $30 / 04 \ldots \ldots \ldots \ldots \ldots$ & $1.078 \mathrm{ac}$ & $965 a b$ & $1.149 b$ \\
\hline $7^{\mathrm{a}} \ldots \ldots \ldots \ldots$ & $10 / 05 \ldots \ldots \ldots \ldots$ & $899 \mathrm{~cd}$ & $877 \mathrm{bc}$ & $1.055 b$ \\
\hline $8^{\mathrm{a}} \ldots \ldots \ldots \ldots$ & $20 / 05 \ldots \ldots \ldots \ldots . . . .$. & $644 \mathrm{e}$ & $657 \mathrm{~cd}$ & $702 c$ \\
\hline Médias & & $893 \mathrm{C}$ & $950 \mathrm{~B}$ & $1.282 \mathrm{~A}$ \\
\hline
\end{tabular}

Médias seguidas por letras distintas diferem entre si no sentido vertical para épocas e no sentido horizontal para anos ao nivel de significância de $5 \%$ pelo teste de Duncan. 
Tentativas têm sido feitas no sentido de reduzir a estatura das plantas. Entretanto, os cultivares de porte baixo têm demonstrado maior suscetibilidade a doenças como giberela, septoriose e helmintosporiose.

No quadro 4, encontram-se as alturas médias dos cultivares estudados: - CNT-8, originário do Rio Grande do Sul, apresentou o porte mais alto, diferindo do $\mathrm{BH}-1146$ e, este, do IAC-17, independentemente dos anos e das épocas de semeadura.

QUADRO 4. Altura média das plantas dos cultivares de trigo IAC-17, $\mathrm{BH}-1146 \mathrm{e}$ CNT-8, em oito épocas de semeadura, no quadriênio 1979-82 no Vale do Paranapanema, município de Assis, Sp

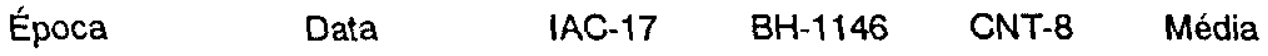

\begin{tabular}{|c|c|c|c|c|c|}
\hline \multirow[b]{2}{*}{$1^{\mathbf{a}} \ldots \ldots \ldots$} & \multirow[b]{2}{*}{ 10/03 ........... } & \multirow[b]{2}{*}{$46 c$} & \multicolumn{3}{|c|}{$\mathrm{kg} / \mathrm{ha}$} \\
\hline & & & $57 \mathrm{~b}$ & $83 a$ & $62 \mathrm{D}$ \\
\hline $2^{\mathrm{a}} \ldots \ldots \ldots \ldots$ & $20 / 03 \ldots \ldots \ldots$ & $56 c$ & $67 b$ & $87 a$ & $70 \mathrm{C}$ \\
\hline $3^{a} \ldots \ldots \ldots$ & $30 / 03 \ldots \ldots \ldots$ & $58 c$ & $69 b$ & $88 a$ & $72 \mathrm{C}$ \\
\hline $4^{a} \ldots \ldots \ldots$ & $10 / 04 \ldots \ldots \ldots$ & $65 c$ & $75 b$ & $89 a$ & 768 \\
\hline $5^{a} \ldots \ldots \ldots \ldots$ & $20 / 04 \ldots \ldots \ldots$ & 700 & $84 b$ & $89 a$ & $81 A$ \\
\hline $6^{a} \ldots \ldots \ldots$ & $30 / 04 \ldots \ldots \ldots$ & $70 b$ & $85 a$ & $88 a$ & $81 \mathrm{~A}$ \\
\hline $7^{\text {男 }} \ldots \ldots \ldots \ldots$ & $10 / 05 \ldots \ldots \ldots$ & $75 c$ & $87 a$ & $81 b$ & $81 \mathrm{~A}$ \\
\hline $8^{a} \ldots \ldots \ldots$ & $20 / 05 \ldots \ldots \ldots$ & $68 c$ & $83 a$ & $78 b$ & $76 \mathrm{~B}$ \\
\hline Médias ... & & $64 C$ & $76 \mathrm{~B}$ & $86 A$ & \\
\hline
\end{tabular}

Médias seguidas por letras distintas diferem entre si, no sentido horizontal, entre cultivares dentro de época e, no sentido vertical, para a média entre as épocas, ao nível de significância de $5 \%$ pelo tesle de Duncan.

Dos anos em estudo, 1982 determinou o maior porte médio das plantas dos tr cultivares $(83,02 \mathrm{~cm})$, diferindo estatisticamente dos demais. Nesse ano, ocorreu o maior índice pluviométrico no quinquênio, com significativo ataque de doenças causadas por fungo nas folhas, confirmando os resultados de FELíCIO et. al. (1986). Segundo HANSON et al. (1985), variedades de trigo semi-anās recebem cerca da metade do hidrato de carbono que produz uma planta na formação dos grãos, ao passo que aquelas de porte alto, como as do presente irabalho, recebem somente um terço desse elemento produzido pelas plantas. Com base nessa afirmativa e devido aos altos índices pluviométricos ocorridos nesse ano, a tendência das plantas de porte alto seria mostrar baixa produtividade, como foi vorificado, pois apresentaram maior formaçăo de massa verde. 


\section{CONCLUSŌES}

1) A melhor época de semeadura, independentemente de cultivares, foi o período entre o terceiro decêndio de março $(21$ a 30/3) e o primeiro decêndio de abril ( $\mathbb{P}^{2}$ a 10/4).

2) Os períodos entre o primeiro decêndio de março (1ª 10/3) e o segundo de maio (11 a 20/5) não sāo favoráveis à semeadura de trigo no Vale do Paranapanema.

3) A melhor época para rendimento dos cultivares, segundo o seu grupo bioclimático, situa-se de 20/3 a 10/4 para os cultivares de ciclo tardio; de 20/3 a 30/4, para os de ciclo precoce, superprecoces.

4) Entre os cinco anos estudados, destacou-se o de 1979, com condições climáticas mais favoráveis à cultura.

5) O cultivar de trigo de ciclo tardio CNT-8 foi superior em rendimento de grāos, sendo estatisticamente superior aos demais.

\section{REFERÊNCIAS BIBLIOGRÁFICAS}

BAYMA, A. da C. Trigo. Rio de Janeiro, Serviço de Informaçāo Agrícola, 1960. 2v. (Estudos técnicos, 14)

CAMARGO, A.P. de. Aptidão climática para as culturas da soja, girassol e amendoim no Estado de São Paulo. In: ZONEAMENTO da Aptidão Ecológica para a Cultura da Soja, Girassole Amendoim no Estado de São Paulo. São Paulo, Instióleos/Secretaria da Agricultura, 1971. p.2-28.

CAMARGO, M.B.P. de; ALFONSI, R.R.;ORTOLANI, A.A.; PEDROJÚNIOR, M.J.;BRUNINI, O. \& CHIAVEGATO, O.M.D.P. A seca de 1985 no Estado de São Paulo. OAgronômico, Campinas, 38(1):31-44, 1986.

Felício, J.C.; CamaRgo, C.E. de O.; CAMARGo, M.B.P. de; CASTRO, J.L. de \& BARROS, B. de C. Trigo: três épocas de semeadura em Capão Bonito, SP, no período 1981-85. Bragantia, Campinas, 47(2):255-275, 1988.

; FREITAS, J.G. de; FERREIRA FILHO, A.W.P.; BARROS, B.de C. \& CAMARGO, M.B.P. de. Avaliaçāo de genótipos de trigo para a região do Vale do Paranapanema no quadriênio 1981-84. Bragantia, Campinas, 45(2):257-277, 1986.

HANSON, H.; BORLAUG, N.E. \& ANDERSON, R.G. Trigo en el tercer mundo. México, Centro Internacional de Mejoramiento de Maiz y Trigo, 1985. 166p.

KALCKMANN, R.E.; ARRUDA, A.A.G. de; HOELTGEBAUM, F.; POPA, W.; BALDANZI, G. \& GODOY, L.C. de. Regiōes de trigo no Brasil (1" aproximação). Pelotas, Serviço Gráfico do IBGE, 1965. 104p. (Estudos técnicos, 28) 
LUZ, W.C. da. Influência do período de umidificação pós-inoculação na reação de cultivares de trigoà mancha foliar (Cochliobolus sativus). In: REUNIĀONACIONALDEPESQUISA DETRIGO, 12., Cascavel, 1982. Resultados de pesquisa. Passo Fundo, EMBRAPACNPT, 1982. p.186-191.

MOTA, F.S. da. Clima e zoneamento para a triticultura no Brasil. In: FUNDAÇÄO CARGILL. Trigo no Brasil. Campinas, 1982. v.1, cap.2, p. $29-94$.

OSÓRIO, E.A. Variedades e melhoramento. In: FUNDAÇĀO CARGILL. Trigo no Brasil. Campinas, 1982. v.1, cap.5, p.147-197.

PERRIN-JAQUET, H. Técnica da cultura de trigo. Belo Horizonte, 1951. 100p.

PIMENTEL-GOMES, F. Curso de estatística experimental. 4.ed, rev. ampl. Piracicaba, Nobel, 1970. 430p.

RAIJ, B.van; SILVA, N.M. da; BATAGLIA, O.C.; QUAGGIO, J.A.;HIROCE, R.; CANTARELLA, H.; BELLINAZZI UÚNIOR, R.; DECHEN, A.R. \& TRANI, P.E. Recomendaçōes de adubação e calagem para o Estado de São Paulo. Campinas, Instituto Agronômico, 1985. 107p. (Boletim técnico, 100)

SILVA, A.R. da. Trigo no sul do Mato Grosso. Campo Grande, Instituto de Pesquisa Agropecuária do Oeste, 1971. 24p.

TEIXEIRA, E.F. O trigo no sul do Brasil. São Paulo, Linotype, 1958. 300p.

THORNTHWAITE, C.W. \& MATHER, J.R. The water balance. Centerton, Drexel institute of Technology, 1955. 104p. (Publications in Climatology, v.8, n 1). 